\title{
Spirituality and Healing
}

\author{
David Tacey \\ Emeritus Professor of Humanities, La Trobe University, \\ Melbourne, Australia
}

\begin{abstract}
Defining spirituality as the art of making compassionate connection, this article makes connections between spirit, the sacred, wholeness, and the soul. The article offers some reflections on the timeliness of what the author sees as the new direction of spirituality toward wholeness and the decline of religion in Western societies. The article discusses the "psychological turn" in spirituality, and psycho-spiritual healing using the example of anxiety; and makes some points about spirituality and the healing professions, healing professionals, and our practice.
\end{abstract}

\section{Waitara}

Whakahauhia ake nei te atuatanga he huarahi herenga aroha, ko tā tēnei tuhinga he whaiherenga mai i te wairua, te tapu me te ngākau. He hokinga whakaaro ēnei kōrero ki te wā tika, e ai rā ki tā te kaituhi, ki te ara hou o te atuatanga ki tōna āhua katoa me te hekenga haere iho o ngā hāhi i ngā hāpori Hauāuru. Ka matapakihia te whakaarotanga kē-āhinengaro e pā ana ki te atuatanga, me te haumahu-ā-hinengaro à-wairua whakamahia ake nei te anipā hai tauira; ka whakaarahia ake ètahi āhua pā atu ki te atuatanga me te rōpū haumahu, ngā kaihaumahu me à tātou whakawaia.

Keywords: spirituality; healing; spirit; sacred; wholeness; soul; wave-particle duality

“The approach to the numinous is the real therapy.” (C. G. Jung, 1973, p. 377)

What is spirituality? This is a question on many people's minds at the moment, as this term becomes increasingly popular. In the modern West, spirituality is different from spiritualism with which it is often confused. Spiritualism relates to ghosts, mediums, séances, and channelling. It has links with magic, spells, and shamanism. It is more concerned with spirits than with spirit as such. It often seeks contact with spirits of the dead. In Indigenous cultures the line between spirituality and spiritualism is often blurred and Indigenous spirituality has a shamanistic dimension, especially in terms of ancestral spirits.

Spirituality is difficult to define and attempts to define it often fail. It is a broad term and

Tacey, D. (2016). Spirituality and healing. Ata: Journal of Psychotherapy Aotearoa New Zealand, 20(1), $19-33$.

DOI:10.9791/ajpanz.2016.03 ( $)$ New Zealand Association of Psychotherapists Inc. 
contains many perspectives. Some define it as the search for meaning, where such a search can involve reaching beyond the visible world to unseen presences. My current definition is that spirituality is the "art of making compassionate connections". It seeks to make links with the major areas of our experience: others, soul, nature, and cosmos. Those who are religious might personify the intelligence of the cosmos as God, Allah, Yahweh, Ao, Hine Nui Te Po, Goddess, Kunappipi, World Spirit, Tao, Indra's Net, World Soul, Anima Mundi, Buddha Mind, Brahma, Vishnu, Shiva, Christ, Holy Spirit. There are countless ways of personifying the sacred, and I do not regard any of these as more or less credible.

The sacred is ultimately a great mystery beyond all description and every culture except our present secular one has attempted to encompass it. I am a relativist when it comes to the sacred but this does not lead me to nihilism because I respect all attempts to express the inexpressible. No one culture can claim to have ultimate truth. I come from a JudeoChristian background and tend to view the metaphysical through that lens, but I am not evangelical; I have an open mind and respect the sacred in all its diverse forms. Rather than fear the diversity of sacred expressions, I celebrate them. For reasons I give below, the search for connectedness with the sacred is on in earnest at the moment.

Today there are many forms of practice associated with spirituality. Some relate to religious traditions, while others do not, and some are drawn from secular and religious contexts. Although it is common today to see spirituality as a life-long quest or search, in most ancient traditions it is seen not so much as a heroic accomplishment as an awakening to a reality close at hand. Spirit is not conceived as far off, a result of great striving, but closer than your own breath. It is typical of our ego-driven society to construct spirituality as yet another thing that we have to do. But often the harder we strive for spirituality the less we find it.

To embrace spirit involves experiencing connections that are always already present; it is not that we make them, we discover them. Mystics tell us that spirit seeks us even as we seek it. Therefore, to try too hard is to miss the mystical dimension of our experience. This is where spirituality shades into mysticism; the awareness of a pre-existing reality that is supportive and aware of us. In the Jewish Kabbalah, spirituality is called the "quality of bestowal". In Kabbalah, one has to experience this bestowal or gift to know what spirituality is.

My university training did its best to knock the sense of the sacred out of me because in the current paradigm of knowledge there is no room for it. All I can say is that I am pleased that my training failed in this respect. A number of factors conspired against it: growing up in a family with a faith commitment, growing up alongside the Aboriginal cultures of central Australia, and my personal experience which suggested that the world is more mysterious than rationality is able to grasp. My history, geography, and experience all proved stronger than the secular conditioning or brain-washing meted out by the university. As a professor for the last 30 years, I was virtually working behind enemy lines in the university system.

Most spiritual traditions argue that we have the capacity for spiritual experience right now but do not know it. Thus spirituality involves silencing the rational mind with its constant chattering and conceptualisations and turning toward another part of mind that is rarely used or developed. Buddhism is very good at doing this. If Western culture is leftbrained, analytical, and reasoned, spirituality involves switching to the other hemisphere, the right brain, which is synthetic, receptive, and imaginative. That is why many of my generation switched religious allegiances from West to East. To switch from rational analysis 
to soulful attunement involves quieting the dominant mind, and that is why relaxation is so important for spirituality.

Some find their way to spirituality through activities such as meditation, prayer, reflection, nature walks, swimming, writing one's thoughts, contemplation of art, dream work, deep listening to nature and to others, etc. There are many ways to spirituality, but it is not so much an activity as it is a state of mind. It involves relaxing into a unifying vision that supports ourselves and creation. This cannot be done without imagination and intuition. Spirituality could be called prayerful attention to the mystery of being, and finding oneself within this mystery, not apart from it. In the past, religions helped people to achieve this goal; in today's secular society most have to do it alone, with a little help from their friends and therapists.

\section{The Keynote of Wholeness}

Spirituality is the art of connecting oneself as a psychological whole with the world as a cosmic whole. The idea of wholeness is central to contemporary spirituality and, in this regard, it contrasts markedly with traditional, religious spirituality which was concerned with perfection. Those who set perfection as their standard, ultimately become pious hypocrites because we are not capable of perfection. Perfection has been shown to be an impossible and even persecutory goal. At least, that is how it is seen today. Wholeness is more attainable and, as a modern ideal, is influenced by therapeutic practice, especially by Jung and Rogers, each of whom posited that gathering our parts into a larger whole is a transformative and healing experience.

While perfection seeks to suppress or transcend our dark side, using spirituality as a defence against the body, emotions, feelings or sexuality, for instance, wholeness seeks to embrace these elements in a larger totality. Wholeness is critical of what it calls "spiritual bypassing", a term introduced by John Welwood (2000) which means avoiding unresolved issues in a bid to aspire to transcendental heights.

In this regard, the term "spirituality" can be misleading. It can evoke ideas of piety, devoutness, and righteousness, which were all aspects of Western spirituality in the past. But spirituality has undergone a sea-change in recent times. This was made apparent by feminist theologian Sandra Schneiders:

The term "spirituality" no longer refers exclusively or even primarily to prayer and spiritual exercises, much less to an elite state or superior practice of Christianity. Rather, from its original reference to the "interior life" of the person, usually a cleric or religious, who was "striving for perfection", for a life of prayer and virtue that exceeded in scope and intensity that of the "ordinary" believer, the term has broadened to connote the whole of the life of faith and even the life of the person as a whole, including its bodily, psychological, social, and political dimensions. (1989, p. 679)

If people say they are seeking spirituality this does not mean they are seeking to be holy, saintly or even "good" in the conventional sense. It simply means they are seeking to be 
authentic, legitimate, and whole: wholeness is the new holiness. Those on this path want to recognise and experience every aspect of their lives, every corner of their souls, no matter how shocking or perturbing these might be. The background idea, also borrowed from psychotherapy, is that the recognition of our various parts can have a healing effect on the personality. Seeing what we had not seen can be liberating, and the hope is that the darker aspects of the psyche might lose some of their malevolent or "evil" power by being brought into the light of consciousness. If the dark side is expressed rather than repressed, it loses some of its autonomy and is brought into the community of the psyche.

With this in mind, and given the long historical association of spirituality with perfection, some are qualifying the term to indicate that the dangers of spirituality are acknowledged, using terms such as "embodied" spirituality or "integral" spirituality. Spirituality remains ethical, but is no longer moralistic, and is not interested in maintaining a false persona simply to aspire to unattainable heights. Perfection has been rejected as unviable with wholeness replacing it as a new ethic. Change has come to the life of the spirit, rendering irrelevant the dusty old tomes that preach perfection. When tethered to the ideal of perfection, humanity was on an unecological and destructive course, and it seems that the forces of evolution have intervened to stop our madness. Self-correcting forces in the psyche have directed it toward a more sustainable course.

This adjustment to a psycho-spiritual ecology occurs at the same time as we are called to a new ecological awareness in our relations with the natural world. As within, so without. Thus the internal and external forms of ecology arise simultaneously, and we cannot have one without the other. The need for a world ecology can only be based on a new awareness of an inward or spiritual ecology. The problems with humanity and nature mirror each other, and both have arisen as a result of debilitating dualisms that must be overcome. We look forward to a spirituality which strives toward the integration of the whole person, an "ecology of the soul" that could form the basis of a new consciousness.

\section{Why Now?}

There is a connection between spirituality's new direction toward wholeness and the decline of religion in Western societies. As religion has waned, some of its old frames of reference and values declined with it. Spirituality once represented the inner life of religion, its living core, and as such it was disciplined and controlled by religion. Today spirituality has been, as it were, deregulated, and taken up by the secular majority without any regard for religious authority. This has made spirituality free-wheeling, liberated from the past and democratic, as William Johnston (1996) explained:

To the surprise of many, the term spirituality has become democratized since monastics first disseminated it. Ideals that for centuries an elite viewed as virtually unattainable now prompt spiritual growth in everyone. In a word, a "spirituality revolution" during the past thirty years has democratized pursuit of holiness. (p.131)

Spirituality still exists as the inside life of traditions, but this use of the term is now marginal compared with the vast numbers who use the term in a different way. Religious people often 
complain that spirituality has been hijacked by the secular and that it has become undisciplined. It is hard to define spirituality because everyone seems to have their own version of it. Diversity has resulted in a slightly chaotic picture about what spirituality is and what it looks like. On the other hand, secular academics complain that contemporary spirituality is flaky and escapist; it seems to them to be an odd thing to have arisen in an increasingly secular world.

All these criticisms are fair in the contexts in which they are made. The religious are shocked that the essence of their traditions is in the wider public domain, unregulated, wild, and free. To them it seems a desecration of the sacred, but this is what happens when religious institutions decline. The essence of religion, the religious impulse or what we are calling "spirituality", is ineradicable (Hay, 2007); we cannot get rid of it, as it belongs to human nature. The striving for an unseen power behind creation, a deeper purpose behind our lives, is endemic in human beings, and it will seek expression whether religious institutions exist or not.

To the highly rational, spirituality is inexplicable and always flaky. After all, given the mental landscape rationalists inhabit, it makes no sense. But what rationalists fail to understand is that although our modern world is secular, and becoming more so, this does not mean the spiritual impulse has disappeared. In fact, paradoxically, as formal religion has gone into decline, the spiritual impulse has, if anything, intensified in our human experience. As sociologist Peter Berger (1999) wrote:

Secularization on the societal level is not necessarily linked to secularization on the level of individual consciousness. Certain religious institutions have lost power and influence in many societies, but both old and new spiritual ideas and practices have nevertheless continued in the lives of individuals. (p.3)

The early modern view of society held out little hope for religion and adhered to secularisation theory which argued that as we became more educated, belief in God and the spiritual would disappear, but the revised sociology has refuted this theory, in keeping with the fact that religion is not going away but, rather, changing its shape, and in Western societies is reappearing as "spirituality".

However, only the surface of society is secular, its official institutions and discourses, unofficially, the spiritual impulse has fallen into the unconscious and become more pronounced. This is why spirituality has become of interest to therapists, counsellors, and psychiatrists, because it often comes up in the course of therapy. This can make the client and therapist uncomfortable and embarrassed, because neither necessarily knows how to respond to the unexpected emergence of a spiritual desire.

\section{The Psychological Turn}

Because the spiritual impulse has fallen into the unconscious, it appears to be more "psychological" than ever. The landscape of human nature has changed since religion has waned. Individuals, not institutions, are now the carriers of the spiritual urge and this dramatically changes the nature of spiritual life. It gives the individual far more authority than 
he or she had in the past. But it also makes the individual confused and bewildered, especially if he or she has decided, along with society, that there is no God, no metaphysical mystery, no spiritual life. Thus for such people to find that they have to deal with the strange emergence of the spiritual can be profoundly disorienting. Spirituality involves us in a wrestling match with the heart and our inner demons. W. B. Yeats (1939/1991) wrote in his last poem:

Now that my ladder's gone

I must lie down where all the ladders start

In the foul rag and bone shop of the heart. (p. 224)

For Yeats, the "ladder" refers to religious systems that once transported us from the mundane to the heavenly. The loss of this ladder, the vertical pathway to the transcendent, would not be replaced in the short-term by a new ladder, a new religion, but by psychological experience in "the foul rag and bone shop of the heart". In other words, after the collapse of religious culture and the so-called "death of God", we find ourselves having to deal with psychological experience (Griffin, 1988). As Yeats suggested, destiny has condemned us to this activity, since we have been thrown into the heart - or what psychology calls the unconscious against our will and not from our choosing. We need a way of connecting with the divine which is not an upward pathway to moral perfection but a deepening path toward the body, psyche, and the wholeness of personality.

The ladder gives way to the snake; we slide down its scaly back into the realm of our forgotten interiority, which for some can be a kind of hell.

I know this conference is called "Mind, Body, Spirit", but contemporary spirituality can be more about the exploration of soul than spirit. By soul, I refer to the English translation of the Greek word psyche, from which we derive "psychology". In the classical tradition, spirit is masculine (Latin: animus), ethereal, aspirational, and sublime. Soul, however, derives from anima, which is seen as feminine, embodied, a bridge between heaven and earth. Soul is the vessel that contains spirit and transforms it. Soul draws spirituality into a different key, making it earthly and holistic. Thus to my mind we need a quaternity: mind, body, spirit, soul, not just the trinity of this conference's title. A spirituality that is shaped by soul is akin to "individuation", that is, the making of the personality. Some recent works on the spiritual life do not refer to spirit as such, but only to soul, and were written by secular psychologists. Although secular in origin, the psychotherapies find themselves, often in spite of their intentions, dealing with spiritual themes such as connecting to the heart, finding the inner self, relating to cosmic forces, and attending to guiding dreams.

This may be one reason why some religious people fail to understand what the modern world means by "spirituality" and denounce it as fraudulent. In the past, spirituality referred to the overcoming of the self in acts of humility, self-surrender, and compassion. Today, however, spirituality refers not to the overcoming of the self but to the fulfilment of the self, and this gives contemporary spirituality its so-called "narcissistic" character, as claimed by traditionalists. However, genuine spirituality does not focus merely on the ordinary self, the ego, but moves beyond it to the discovery of an objective life within the self, which is what mystics call the "God Within". To outsiders, this may look like narcissism in that it is inwardly focused but the modern search is for the divine spark within the personality. This 
places the new spirituality in the tradition of gnosticism, mysticism, and esotericism.

In this case, "transcendence" has been redefined. It used to refer to the abnegation of self through surrender to God and good works but today it has a more psychological meaning: it refers to the art of transcending ego by exploring deeper regions of the personality. One "overcomes" not the self but the ego, and in so doing one liberates the spirit within. For those for whom spirituality is synonymous with social justice and good works, this introverted spirituality is frowned upon, but it is what we have been bequeathed by modernity. With much that is traditional collapsing around us, we have been thrown back on ourselves and the discovery of the spiritual aspect of the interior self is the distinctive characteristic of modern experience.

\section{Healing}

Those who suffer often become interested in spirituality as a means of enduring and transforming their suffering. Those who experience painful life transitions, such as from childhood to adulthood, or the midlife transition, or a near-death experience leading to a return to life, often find themselves dealing with spiritual questions as a means of negotiating the crisis (Tacey, 2010). Only by connecting to deeper values and meanings can one shed a previous self and take on a new identity with confidence. Spirituality and rites of passage have typically appeared together in the initiation ceremonies of Indigenous and tribal cultures, as in the induction rites of ancient religious traditions. To move from an innocent to a cultural state, from ignorance to wisdom, is a shift that requires the support of transpersonal forces and contact with what is considered to be sacred. Such movements in life cannot be engineered by the ego or established by a merely rational point of view. They require depth, intuition, and insight, all of which are the preserve of the wisdom traditions and commonly at odds with secular or worldly pursuits.

We live in a time which is crying out for the healing that comes from spiritual experiences, from the feeling of being connected to forces beyond the self. This connection produces relief, transcendence, and joy. Our society has numerous dangerous substitutes for this experience, including substance abuse, consumerism, over-working, over-eating, undereating, risk-taking behaviour, and various kinds of extreme activity or sensationalism, all of which simulate a sense of living outside the self. We have lots of substitutes for ecstasy because the real thing is not the domain of secular society which is unable to understand the needs of the spirit but nonetheless caters indirectly, and often lethally, to its needs. The modern self is subject to ever-increasing pressures, and succumbs to loneliness, alienation, and depression. Is there any wonder that spirituality is sought out today, and especially today, when the embattled self is in need of transcendence and reconnection?

There is something about connecting with forces beyond the self that brings calm and a reduction of anxiety, and yet our secular society, unable to meet such needs, is constantly forcing us to live atomised lives as cocooned egos. The longing to surrender to forces beyond the self is innate, but in our society this longing has nowhere to go, other than in profane versions of self-surrender, such as those demanded by institutions, governments, political parties, and ideologies. Apart from that, society can only offer us negative pathways of transcendence through the patterns of addiction and excess: 
Addiction is the negative side of spiritual seeking. We are looking for an exultation of the spirit; but instead of fulfilment we get a short-lived physical thrill that can never satisfy the chronic, gnawing emptiness with which we are beset. (Johnson, 1987, p. vii)

\section{Spirituality and Healing Professions}

In psychiatry and medicine, spirituality is increasingly referred to in positive terms (Koenig, 2002), though less so in academic psychology which seems particularly resistant to spirituality with the important exception of Robert A. Emmons (1999). This largely positive view represents a significant reversal: not long ago spirituality was frowned upon in medical discourses as delusional and more likely to be a cause of - rather than a cure for - illness. However, the iron-clad rationalism of modernist science has been rejected by many contemporary scientific thinkers who freely admit that humanity is not a product of chemicals and materials but a complex field which is directed toward meaning and purpose. Such a reversal is evident, for instance, in this statement on the website of the Royal College of Psychiatry (RCP) in the United Kingdom: "Spirituality involves a dimension of human experience that psychiatrists are increasingly interested in, because of its potential benefits to mental health" (RCP, 2009).

What was regarded with suspicion 20 or 30 years ago is being viewed with new eyes today, but note the pragmatic tone here: spirituality is only of value if we discern practical benefits in it. This is still a long way from altruistic spirituality which is concerned with the spirit not because of what it does for us but what it does for others and on behalf of the Absolute Other.

Research shows it is often the suffering patient who brings the question of spirituality into the clinical setting (Roach, 1997). Therefore, spirituality has arisen as an item on the agenda of the health professions not because professors of medicine have had conversion experiences but because suffering clients want to bring this vague and ill-formed concept into the therapeutic setting. Today we can speak of a client-led or grassroots recovery of the spiritual in health and healing (Swinton, 2001). The person suffering from a neurosis, mental illness, addiction or compulsion expresses the view that a lack of spiritual meaning in his or her life might have something to do with their malady or despair. In our secular era, people often have inadequate language to express this feeling of spiritual absence, but they grope toward it, using whatever resources they can find from religion, popular music, movies, conversation or intuition.

The attempts by suffering patients to express their illness in terms of a spiritual malaise represents a challenge to the healing professions, which have typically been secular and materialistic. As psychiatrist Andrew Powell (2005) put it:

Patients' attempts to talk about their spiritual beliefs and concerns are often met with incomprehension and mistrust. Sometimes the chaplain will be called in but frequently the patient will be advised not to dwell on such matters, or else will find those experiences dismissed as delusions or hallucinations. ... The psychiatrist, frequently beleaguered and trying to maintain an emergency service with pitifully inadequate resources, relies first and foremost on medication, second on social support networks, third on psychological interventions where deemed appropriate 
and least of all on spiritual sources of strength. On top of that, he or she is three times less likely to hold a religious faith than the patient. (p.167)

There is often a gap, what I have referred to as the "spirituality gap" (Tacey, 2003), between the spiritual demands of the client and the assumptions and values of the health professional. The doctor or therapist can fall in the gap, by claiming incomprehension and refusing to engage, or he or she can attempt to cross the gap by asking questions of the client's interests, and perhaps sharing his or her spiritual views.

However, if the practitioner has their own spirituality or faith, the literature suggests that this can be shared but ought not be imposed on the client. The clinic is not a church or temple and if there is an imposition of belief from above, the healing experience unique to the patient may not be realised and may even be thwarted. The task of the therapist is to act as midwife to what needs to be brought to birth in the soul. This means one's own prejudices and beliefs have to be bracketed and one has to resist the temptation to impress on the patient one's own worldview. This is as true in the education and teaching professions as it is in health and medicine.

\section{The Healing Presence Within}

Healing is ultimately self-healing, although most of us have no way of knowing this. The "self" that heals is not the ordinary self, but something more mysterious which is nevertheless part of our interiority. It sounds contradictory, but there is an objective presence at the core of our subjectivity, and whether we call this soul, spirit or "god within" makes little difference to the reality of the presence. Healing begins when a patient has sensed the presence of an other at the core of his or her being and makes an attempt to contact that presence. This is the basis, I take it, of the traditional claim about the healing power of prayer. When we contact the universal source at the core of our being it seems to respond in some way; perhaps discernible only to those who listen attentively and are closely attuned. The prayerful and contemplative attitude helps in the healing process.

The idea of a spiritual presence at the core of our subjectivity is new to Western medicine, which tends to externalise the healing process, seeing it as the result of one's encounter with the doctor or the result of medical interventions and pharmaceuticals. The inward presence is, alas, often absent in Western religions as well, where it is sometimes felt that only the saint or the monastic, not the ordinary person, has access to spirit. If ordinary people claim this kind of experience they are treated with suspicion or regarded as cranks, blasphemers or frauds. In the West we have downplayed the healing resources of the body-mind-spirit, which is why so many of us are at the mercy of the external forces of healing.

I am not talking here about miraculous cures through the spirit. Such might indeed happen but if they occur it is due to the workings of the divine and not to our asking for a cure. On this point, I have argued with colleagues in the healing professions, including psychiatrists with interests in spirituality, who seem more concerned with cure than healing. To me, healing is more important than cure, and by "healing" I mean a reconciliation within a person to their suffering, not necessarily the elimination of their symptoms. Healing may lead to cure but it may not. In my view, if the illness is still confined to the mental domain, 
there is more chance of a cure through contact with the numinous. However, if a neurosis has been somatised, there could be less chance of recovery since once the body has somatised the illness, working with the mind or spirit might be less effective.

But how does this work? How does contact with the numinous bring about healing? In this regard, I have to concede, I work primarily with my intuition and metaphor. I like the metaphor that has emerged from theoretical physics, about waves and particles, and would like to apply this to healing and recovery. In physics and chemistry this is called waveparticle duality.

\section{The Wave-Particle Paradox}

Many of us imagine the self to be a discrete entity, solid, formed, and known. But this could be an illusion of our making, albeit a useful illusion that allows us to act efficiently in the world. Researchers of the unconscious have found that the self has no definite boundaries and at its depths it trails off into mystery. To borrow the metaphor from physics, what we had previously thought of as a solid entity may turn out to be a wave of infinite extension. Quantum physics discovered that the smallest elements of matter behave in one moment as particles and in another as waves. As particles, they are discrete and separate, and can be "split" to release energy. As waves, they behave less like bits of matter and more like bands of light or energy, reaching out to eternity. They cannot be confined or boxed in, but participate in an ocean of being as it were.

This suggests a certain paradoxical instability at the heart of matter. Matter looks stable to the eye but from the perspective of microphysics, the world is fluid, uncertain, and even bizarrely so. Einstein argued that all particles have a wave nature, and vice versa. Heisenberg, Max Planck, and others refined and changed the theory. Needless to say, this discovery shattered the prevailing views of Newtonian physics, and its ramifications are still being felt today.As Brian Greene (1999) put it in The Elegant Universe, "Matter has been dematerialized" (p.104). Thus, mystical religion and theoretical physics are moving in similar directions.

I like to apply the wave-particle duality to psychology as it can help us conceptualise the spiritual dimension of healing. Like matter, the self is only relatively stable. At its depths, it too can lose its solidity and appear as a wave or a fluid process. I would suggest that as psychological and spiritual beings we live simultaneously as waves and as particles.

As particles, we are distinct beings, physical and discrete, each with our unique personality and makeup. As waves, we are not so distinct; we are similar to each other and participate in the cosmos in predetermined ways; we are spiritual beings, fluid, open-ended, and connected to other waves; we are receptive to archetypal currents that course through us. The particle is the ego or conscious self, and the wave is the infinite expanse of the unconscious. This double aspect of the self has long been known to civilisations but not expressed in this psychological way.

The Dionysian rituals of ancient Greece are examples of the experience of the numinous as a healing field. The point of the Dionysian ritual is to lose the solidity and separateness of the self and participate in the ocean of being. Modern rituals, too, seek to lead us away from the particle to the wave. Such experiences are referred to as grace, love or transcendence. Indeed, the very word "ritual" derives from the same Latin root as "river", that which flows. 
The wave-like connection is what we today call "spirituality", namely, the capacity to feel connected to the cosmos and the totality of life. This is the secret of ecstasy. The word "ecstasy", from the Greek ek-stasis, meaning to be "outside the self", points to the pleasurable experience of transcendence.

\section{Anxiety as a Spiritual Problem}

My contention is that as soon as we experience ourselves as waves, there is a healing effect on consciousness. When this connection is restored, we overcome ego-bound existence and feel ourselves to be part of a larger whole. The ego's concerns and worries are dropped and we feel renewed. It is burdensome to be confined to the ego and its tiny world. As Freud correctly observed, the ego is the seat of anxiety, and when we move outside the ego our anxiety - which is productive of disease and neurosis - falls away. By the same token, a society which is bound by the ego is hounded and undermined by anxiety. There is a considerable public cost to living our lives without a sense of spirit which releases us from the prison-house of ego and its often unbearable tension and limitations.

Recent figures in Australia and New Zealand suggest that anxiety, and its counterpart, depression, are escalating at alarming rates. About 20 years ago, when I first looked into these figures, one in five Australians were suffering from, or would suffer at some stage from, anxiety and/or depression. In the last couple of years, these figures have increased: it is now one in four, not one in five; which means a quarter of the population is besieged by anxiety. It is little wonder that epidemiologists are now arguing that there is something wrong with our lifestyle, indeed, with our civilisation itself. If we stifle the spiritual we stifle ourselves and live less rewarding lives.

Australia and New Zealand have, on a per capita basis, the highest suicide rates in the world. Naturally a lot of medical professionals and policy makers are concerned about these figures but are they aware that suicide rises in proportion to the absence of spirit in people's lives? This means that the body-mind-spirit nexus is a public health issue, not merely a matter of personal choice or intellectual taste. The fact is that we are not designed to dwell forever in the ego. This has long been known to human knowledge, which is why ritual and liturgy played such a huge role in people's lives in the past. Today we don't know what to do with the spiritual impulses inside us, impulses that require us to break out of the ego and overcome its boundaries.

This is why in modern societies there is so much dependence on drugs, alcohol, and other substances. We know there is more to life than what we are living, and we are inclined to say, to hell with the cost and danger, I will take this or that drug and find the release for which I crave. This craving, although often expressing itself in illegal or criminal ways, is actually derived from the spiritual urge to transcend. In 1929 psychologist C. G. Jung said, "The gods have become diseases" (Jung, 1929/1967, para. 54), recognising that the secular condition of modernity was doing nothing to placate or fulfil the spiritual urges in his patients. He felt that many were eaten up by unrecognised and unrealised spiritual urges. At the time, Jung was seen as a crank but today we are more inclined to take what he said seriously.

There is a hidden dimension of our lives that is real and needs attention, especially in times of illness and despair. From a spiritual point of view, mental illness might be described 
as alienation from our source. Religions have long known this, and that is why the rituals of religions are about "communion", that is, binding back to the divine. But in a non-religious time, we still need to have the experience of communion, which restores the soul and the spirit. When we transcend ego boundaries in rituals, psychotherapy, art or meditation we return to the ocean of being and are restored. Sometimes our intellect gets in the way of our need for nonrational experiences of transcendence. We deny ourselves this release and even feel embarrassed if we discover our need for such experiences. Society introjects its own views inside us as a persecutory superego.

The tranquillity that we experience as we walk beside the ocean, the calm that descends as we look across a landscape or move through a ferny gully is related to the experience of the particle returning to the wave. The therapeutic effect of music or dance, which takes us outside the ego into "waves" of sound and movement, is expressive of the joy experienced as we enter the wave. The wave-like effect is what religions seek in their rituals. In liturgy, prayer, and ceremony, the isolated self is eclipsed and we interact with forces beyond ourselves. Religions build communities in ways that secular society never can, because they reach beyond individuality and draw from us our longing to connect to our origin. But it is hard to find our way home in a secular society which has no respect for spiritual needs and can only offer us religious substitutes, addictions or drugs to satisfy our craving.

\section{Healing as Reconnection}

There is little doubt that, with the absence of official forms of transcendence, the royal road to spiritual experience is suffering. This is the typical pathway to move beyond the ego. If we cannot return to the source through the doorway of mythos, the only way is through pathos. With culture committed to the ego rather than spirit, nature gets its revenge. Mental suffering is often the trigger to a religious conversion or a spiritual point of view. When life proceeds normally, and the task of social adjustment is successful, there may never arise the need or opportunity to find a relationship to a spiritual core. But when the normal self has been ruptured, the only option left, apart from running to others for help, is to seek reunion with the wave-like dimension at our core. By so doing, we turn to what is most profound in ourselves, and ask it, implore it, to heal us, to close our wounds and grant us life. This is why so many recovery programs and other methods of dealing with human suffering find themselves moving into the spiritual domain. Of course, the Alcoholics Anonymous movement is prime example of this (Morgan \& Jordan, 1999).

Our society encourages the state of the atomised, discrete, self-sufficient ego, and that is the source of illness in our world. The socially adapted and healthy ego is generally not interested in humbling itself before the divine. It thinks of this as something odd, antiquated, even perverse. This is why the ego must suffer, because it cannot come to the sacred any other way. In normal life, and in going about our business, we live a "particle" existence. We behave like atomised entities, each concerned with his or her self-interest or with a small family group. Beyond these narrow circles of concern, there is no interest in the cosmos at large or with spirit as an active agent in our lives. But as waves, we seek connection to that which is beyond the ego. We extend beyond the particular, breaking its boundaries, and reach for eternity and the stars. 
Thomas Berry (1988) wrote that ecological healing occurs when the world is no longer experienced as a collection of objects, but as a communion of subjects. This formula underpins the creation of community, is at the heart of the ecological vision, and is also at the heart of psychological healing. Healing occurs when we no longer experience ourselves as isolated particles in a world of objects, but when we experience ourselves as waves merging and interacting with other waves. Although I am too old to go to rave parties or trance dances, I imagine that this is the allure of such activities. The prison-house of the ego needs to be opened every now and then. The self may not realise its true nature, which releases bliss, until it experiences itself in relation to a larger reality. The self "comes home" to itself when it glimpses the other which is its origin. Longing is fulfilled when we recover our belonging.

\section{The Art of Spirituality in a Clinical Setting}

For some, this will be merely repeating what you already know and practice, but it may be worth saying. My hope is that the healthcare professions can emphasise spirituality, not formal or organised religion. It is certainly not the job of professionals, whether academics, doctors, psychiatrists, psychologists or counsellors to foist their particular beliefs upon students, patients, clients, and suffering people. Ought we think that patients are somehow "cured" when they have adopted the beliefs of their doctors? Are they "well" when they espouse the things that counsellors think are right? This is not the way to conduct healing, and it cannot be condoned.

The healing professions need to develop an interest in what could be called an "existential spiritual attitude". Clinical discussions could draw the spiritual core out of the person and allow him or her to choose the path that their spirituality will take. Therapy and consultation can help people find the courage to believe in an invisible level of support, but it is not up to the professionals to supply the specific language or creed. That is a personal matter and not the province of those in authority. This makes a generic spirituality all the more attractive and desirable in today's world, and especially important for professional life and ethical conduct.

The aim is to find a large healing framework which is potent enough to evoke a sense of the sacred but loose enough to allow variations on a theme. The professional's task is not to evangelise or proselytise but to encourage people to discover what is life-giving and creative in their experience of the world. In this paper, I have been arguing that healing is achieved when the self connects to that which is "more than" itself. The therapist's belief system, however genuinely held, can act as a barrier to the healing forces within the client's immediate world.

The key for professional practice is to place the patient's experience before our own theories or beliefs, and use the patient's language, not our own, to access and mobilise the healing forces. This requires listening not preaching. The results will be liberating rather than oppressive. The art of spirituality is the art of deep listening, of attunement to the other within and beyond the self. This is spirituality in action, not only as therapeutic content but as clinical method. 


\section{Acknowledgement}

This article is based on an invited keynote speech given on 21 April to the Annual Conference of the New Zealand Association of Psychotherapy, held in Napier, 20-23 April, 2016.

\section{References}

Berger, P. (1999). The desecularization of the world. Grand Rapids, MI: Eerdmans Publishing. Berry, T. (1988). The dream of the earth. San Francisco, CA: Sierra Club Books.

Emmons, R. A. (1999). The psychology of ultimate concerns: Motivation and spirituality in personality. New York, NY: The Guilford Press.

Greene, B. (1999). The elegant universe. New York, NY: Vintage.

Griffin, D. R. (1988). Spirituality and society: Postmodern visions. Albany, NY: State University of New York Press.

Hay, D. (2007). Something there: The biology of the human spirit. Philadelphia, PA: Templeton Press. Johnson, R. (1987). Ecstasy: Understanding the psychology of joy. San Francisco, CA: Harper \& Row. Johnston, W. (1996). Recent reference books in religion. Downers Grove, IL: InterVarsity Press. Jung, C. G. (1967). The collected works of C. G. Jung Vol. 13: Commentary on "The secret of the golden flower (R. F. C. Hull, Ed. \& Trans.). New Haven, CT: Yale University Press. (Original work published 1929)

Jung, C. G. (1973). Letter to P. W. Martin. In C. G. Jung Letters Vol. 1: 1906-1950 (G. Adler, Ed.; p. 377), Princeton, NJ: Princeton University Press.

Koenig, H. (2002). Spirituality in patient care. Philadelphia, PA: Templeton Foundation Press.

Morgan, O. \& Jordan, M. (1999). Addiction and spirituality: A multidisciplinary approach. St Louis, MO: Chalice Press.

Powell, A. (2005). Spirituality, healing and the mind. Spirituality and Health International, 6(3), 166-172. DOI: 10.1002/shi.7

Roach, S. M. (1997). Caring from the heart: The convergence of caring and spirituality. New York, NY: Paulist Press.

Royal College of Psychiatry. (2009). Spirituality and mental health. Retrieved from http://www. rcpsych.ac.uk/mentalhealthinfo/treatments/spirituality.aspx

Schneiders, S. (1989). Spirituality in the academy. Theological Studies, 50(2), 676-697.

Swinton, J. (2001). Spirituality and mental health care: Rediscovering a 'forgotten' dimension. London, UK: Jessica Kingsley.

Tacey, D. (2003). The spirituality revolution: The emergence of contemporary spirituality. Sydney, Australia: Harper Collins.

Tacey, D. (2010). Gods and diseases: Making sense of our physical and mental wellbeing. Sydney, Australia: Harper Collins.

Welwood, J. (2000). Toward a psychology of awakening: Buddhism, psychotherapy, and the path of personal and spiritual transformation. Boston, MA: Shambala.

Yeats, W. B. (1991). The circus animals' desertion. In T. Webb (Ed.), W. B. Yeats: Selected poetry (p. 224). Harmondsworth, UK: Penguin. (Original work published in 1939) 


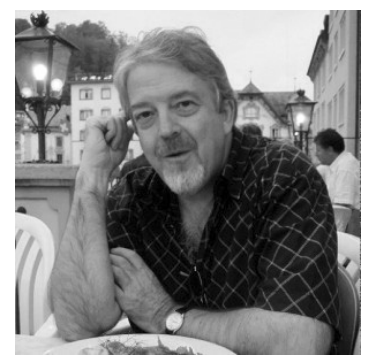

David Tacey is Emeritus Professor of Humanities at La Trobe University, Melbourne, and an interdisciplinary scholar and public intellectual. He has written and lectured extensively on spirituality, religion, youth experience, and mental health. He is a specialist in Jungian depth psychology. He taught short courses at the C. G. Jung Institute in Zürich from 2001 to 2010. $\mathrm{He}$ is the author of 14 books that have been published internationally, some having been translated into Mandarin, Korean, Spanish, Portuguese, and French. Professor Tacey grew up in central Australia alongside Aboriginal cultures, and has a life-long interest in Indigenous issues. He has written on Aboriginal spirituality and on the suicide epidemic in Aboriginal cultures. His most recent book on mental health is Gods and Diseases: Making Sense of our Physical and Mental Wellbeing (2011, HarperCollins). Contact details: D.Tacey@ latrobe.edu.au . 